Int. J. Electrochem. Sci., 12 (2017) 1915 - 1928

\title{
Experimental and Theoretical Studies of 1-vinyl-3- hexylimidazolium Iodide ([VHIM]I) as Corrosion Inhibitor for the Mild Steel in Sulfuric Acid Solution
}

\author{
Li Feng ${ }^{1}$, Shengtao Zhang ${ }^{1,3, *}$, Song Yan $^{2}$, Shenying Xu ${ }^{1}$, Shijin Chen ${ }^{4}$ \\ ${ }^{1}$ School of Chemistry and Chemical Engineering, Chongqing University, Chongqing 400044, P.R. \\ China. \\ ${ }^{2}$ National Engineering Laboratory for Pipeline Safety, China University of Petroleum, Beijing 102249, \\ P.R. China. \\ ${ }^{3}$ Material Corrosion and Protection Key Laboratory of Sichuan Province, Zigong 643000, P.R. China. \\ ${ }^{4}$ Bomin electronics Ltd, Meizhou 514021, P.R. China. \\ *E-mail: stzhang_cqu@163.com
}

doi: $10.20964 / 2017.03 .30$

Received: 10 December 2016 / Accepted: 12 January 2017 / Published: 12 February 2017

In order to explore the corrosion inhibition mechanism of 1-vinyl-3-hexylimidazolium iodide with different concentration for mild steel in $0.5 \mathrm{M} \mathrm{H}_{2} \mathrm{SO}_{4}$ at $298 \mathrm{~K}$, experimental and theoretical studies were carried out. Not only weight loss but also electrochemical experiments reveal that 1-vinyl-3hexylimidazolium iodide ([VHIM]I) has higher inhibition efficiency. And all experiments have good consistency. The inhibition efficiency was more than $96 \%$ comparing with the blank when the concentration was $5 \mathrm{mM}$. It indicates that [VHIM]I adsorbed on the surface of invested metal by forming a film to protect metal. In addition, SEM observation and ATR-IR spectra was used to further confirmed the above. The Langmuir adsorption isotherm was the most proper adsorption model for the adsorption of [VHIM]I molecule on mild steel surface. Moreover, theoretical calculation and molecular dynamic (MD) simulation also manifest that [VHIM]I was absorbed mightily on the metal surface in a parallel mode.

Keywords: corrosion, inhibitor, mild steel, Electrochemical experiments, molecular dynamic simulation, sulfuric acid solution.

\section{$\underline{\text { FULL TEXT }}$}

(C) 2017 The Authors. Published by ESG (www.electrochemsci.org). This article is an open access article distributed under the terms and conditions of the Creative Commons Attribution license (http://creativecommons.org/licenses/by/4.0/). 